Check for updates

Cite this: RSC Adv., 2019, 9, 6444

\title{
Enhanced oxygen evolution reaction on amine functionalized graphene oxide in alkaline medium $\uparrow$
}

\author{
Vijay S. Sapner, (D) Balaji B. Mulik, Renuka V. Digraskar, (D) Shankar S. Narwade \\ and Bhaskar R. Sathe (iD *
}

Development of highly efficient oxygen evolution reaction (OER) electrocatalysts is a critical challenge in the cost-effective generation of clean fuels. Here, a metal-free tyramine functionalized graphene oxide (T-GO) electrocatalyst is proposed to use in alkaline electrolytes for enhanced OER. Moreover, the T-GO and GO nanomaterials are well characterized by SEM, XRD, FTIR, XPS and Raman spectroscopy. T-GO exhibits an electrocatalytic OER with a current density of $2 \mathrm{~mA} \mathrm{~cm}^{-2}$ at a low onset potential of $\sim 1.39 \mathrm{~V}$ and a small Tafel slope of about $69 \mathrm{mV} \mathrm{dec}{ }^{-1}$ and GO exhibits an onset potential of $1.51 \mathrm{~V}$ and Tafel slope of about $92 \mathrm{mV} \mathrm{dec}^{-1}$. Additionally, the current stability and RRDE based diffusion controlled response of the T-GO electrocatalyst are outstanding compared to GO. This study establishes metal free T-GO as an efficient electrocatalyst for the OER and used for cathodic production of hydrogen as a counter reaction in the field of water splitting.

Received 15th December 2018 Accepted 10th February 2019

DOI: $10.1039 / \mathrm{c} 8 \mathrm{ra10286d}$

rsc.li/rsc-advances

In recent years, the synthesis of a variety of electrocatalytic

\section{Introduction}

Energy crises and environmental pollution are among the most important issues worldwide and affect every country. Numerous efforts have been devoted to an alternative path for renewable energy, such as solar cells, chemical to electrochemical energy conversion etc. ${ }^{\mathbf{1}}$ In the electrochemical hydrogen evolution reaction (HER), $\mathrm{H}_{2}$ is produced as an efficient energy carrier for possible future energy systems. ${ }^{2}$ Unfortunately, however, the electrochemical oxygen evolution reaction (OER) is a great challenge in the development of power sources because of its complex mechanism of multi-electron transfer steps and the poor stability of the electrode materials. ${ }^{3}$ The overall water splitting reaction involves the production of $\mathrm{H}_{2}$ and $\mathrm{O}_{2}$ through HER at the anode and OER at the cathode respectively. ${ }^{4}$ Electrocatalytic water splitting (electrolysis) is currently an attractive alternative strategy for energy generation using water and electricity at room temperature. ${ }^{5}$ Water splitting is kinetically hindered by the electron transfer rate due to the unequal electron transfers at the anodic and cathodic compartment, i.e. OER corresponds to four electron transfer $\left(4 \mathrm{OH}^{-} \rightarrow \mathrm{O}_{2}+2 \mathrm{H}_{2} \mathrm{O}+\right.$ $\left.4 \mathrm{e}^{-}\right)$while HER is a two electron transfer reaction $\left(2 \mathrm{H}^{+}+2 \mathrm{e}^{-} \rightarrow\right.$ $\left.\mathrm{H}_{2}\right){ }^{6,7}$ In particular, a high input of kinetic energy to the $\mathrm{OH}^{-}$at the anode and a catalyst with highly abundant active sites are usually required to reduce the overpotential for the OER. ${ }^{8}$

Department of Chemistry, Dr. Babasaheb Ambedkar Marathwada University, Aurangabad, 431004, Maharashtra, India. E-mail: bhaskarsathe@gmail.com

$\dagger$ Electronic supplementary information (ESI) available. See DOI: $10.1039 / \mathrm{c} 8 \mathrm{ra} 10286 \mathrm{~d}$ systems for efficient OER has been reported in the literature, including transition metals, ${ }^{9}$ bimetallic nanomaterials, ${ }^{\mathbf{1 0}}$ metal oxide nanocomposites, ${ }^{\mathbf{6}, 11}$ polymer grafted nanomaterials, ${ }^{\mathbf{1 2 , 1 3}}$ carbon-based nanocomposites, ${ }^{\mathbf{1 4 - 2 0}}$ heteroatom doped nanomaterials, noble metal free nanocomposites ${ }^{21-26}$ and many more. In particular, Ir and $\mathrm{Ru}$ based metal nanoparticles and composites have been widely investigated and achieved some of the highest electrocatalytic activities towards OER. However, their use on large scales as an electrode material is seriously hindered by their high cost, which has prevented their commercialization. Therefore, recent research has tended to focus on development of alternatives to these expensive metal based systems, for example, carbon nanostructures with heteroatoms like sulphide, phosphide, metal oxides, etc. These materials are cost effective and have been commercialized. ${ }^{10 b, 18,26}$ Nanostructured catalysts are of great utility because of the reduced electrode content and high catalytically active surface area achieved by a large surface area to volume ratio. Accordingly, it is an extremely important challenge to develop new, facile and highly reproducible electrocatalytic systems for further enhancement of the OER performance using metal-free carbon-based nanomaterials with abundant active sites and large surface area at the nanoscale. These strategies are also important to further improve the performance of metal-free electrocatalysts for large scale overall water splitting, energy conversion and fuel cell applications. ${ }^{13,22,23,27,28}$

Herein, we demonstrate the highly efficient metal-free tyramine functionalized graphene oxide (T-GO) electrocatalyst with enhanced electrocatalytic activity towards OER. The active functionality of tyramine facilitates the electron transfer 
reaction at the graphene interface ${ }^{29}$ and increases the performance towards OER. Our electrochemical findings suggest that the metal-free tyramine functionalized T-GO electrocatalyst has higher OER activity in an alkaline medium as compared to GO. We propose a plausible electrochemical mechanism to explain the better performance of the T-GO electrocatalyst for OER. More significantly, our electrochemical OER catalyst in alkaline medium outperforms other reported systems from the literature.

\section{Experimental section}

\subsection{Chemicals}

Graphite fine powder (extra pure), sulphuric acid $\left(\mathrm{H}_{2} \mathrm{SO}_{4}\right)$, nitric acid $\left(\mathrm{HNO}_{3}\right)$, thionyl chloride $\left(\mathrm{SOCl}_{2}\right)$, tetrahydrofuran (THF), dimethylformamide (DMF), hydrochloric acid ( $\mathrm{HCl})$, potassium hydroxide $(\mathrm{KOH})$ and acetone, all of analytical grade, were purchased and used without any further purification. Tyramine (99\%) was purchased from Sigma-Aldrich. Deionized (DI) water (18 M $\Omega$ ) from a Milli-Q system was used for all syntheses, purification of electrocatalysts and electrochemical studies.

\subsection{Material synthesis}

Graphene oxide (GO) was synthesized from graphite powder by the modified Hummers method. ${ }^{30}$ The typical synthesis procedure of GO and T-GO was reported in previous work. ${ }^{29}$ In more detail, $1 \mathrm{~g}$ of graphite powder was dispersed in $3: 1 \mathrm{H}_{2} \mathrm{SO}_{4}: \mathrm{HNO}_{3}$ in a round bottom flask, and the mixture was stirred in an ice bath for $30 \mathrm{~min}$ and sonicated further for $6 \mathrm{~h}$ at room temperature. After this time, a black-yellow aqueous suspension appeared. This suspension was further refluxed for $24 \mathrm{~h}$ followed by natural cooling and was then filtered and washed with $1 \mathrm{M} \mathrm{HCl}$ followed by DI water and dried in an oven for $30 \mathrm{~min}$.

$200 \mathrm{mg}$ of the above as-synthesized GO was taken, then $20 \mathrm{~mL}$ of $\mathrm{SOCl}_{2}$ followed by $1 \mathrm{~mL}$ of DMF were added under cool conditions, and this mixture was stirred for $1 \mathrm{~h}$ followed by reflux for $24 \mathrm{~h}$. For further functionalization with tyramine, $20 \mathrm{mg}$ of the above GO-COCl was taken and added into a solution of $10 \mathrm{mg}$ of tyramine in $20 \mathrm{~mL}$ of DMF and sonicated for $30 \mathrm{~min}$ and then refluxed for $12 \mathrm{~h}$. This T-GO suspension was filtered and washed to remove unbound tyramine and other water soluble impurities by using DI water followed by alcohol. A schematic representation of the assembling procedure for $\mathrm{T}$ GO is shown in Scheme 1.

\subsection{Material characterization}

X-ray diffraction (XRD) was carried out on a Rigaku Ultima IV fully automatic high-resolution X-ray diffractometer system, with an X-ray generator operating at $40 \mathrm{kV}$ and $40 \mathrm{~mA}$ at a $2 \theta$ step of $0.01^{\circ}$ at room temperature. FTIR spectra were measured in the $4000-400 \mathrm{~cm}^{-1}$ range on a PerkinElmer Spectrum-I spectrometer with samples prepared as $\mathrm{KBr}$ pellets. Scanning electron microscopic (SEM) measurements were carried out with a JEOL (JSM-7600F) instrument equipped with an energy dispersive analysis of X-ray (EDAX) attachment. Raman spectroscopy was performed by a Raman spectrometer with

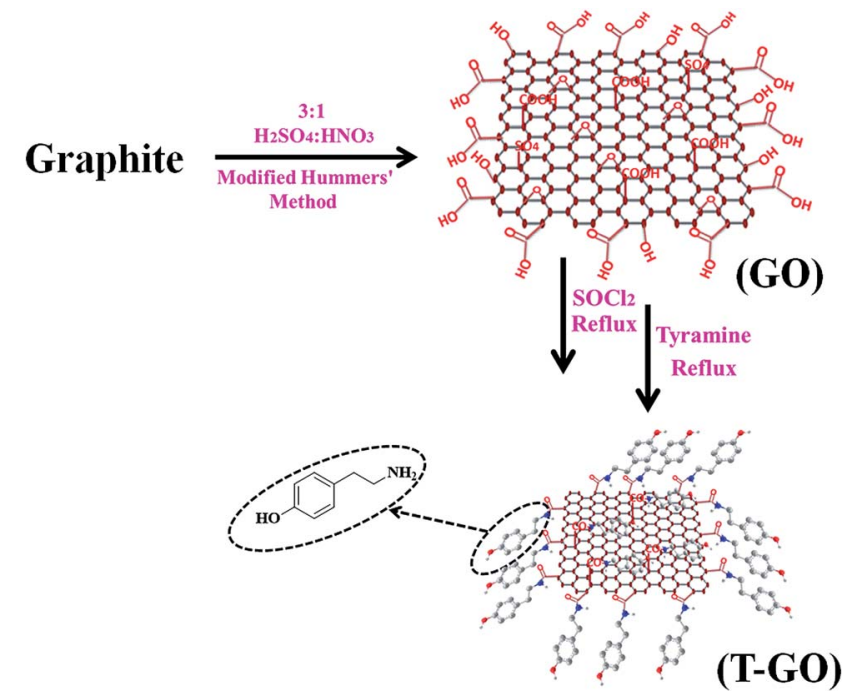

Scheme 1 Schematic representation of tyramine functionalized graphene oxide ( $\mathrm{T}-\mathrm{GO})$.

microscope (Seki Technotron Corporation, Tokyo) with $532 \mathrm{~nm}$ laser equipped with X-ray photoelectron spectroscopy (XPS).

\subsection{Electrocatalytic measurement}

The electrocatalytic performance of the GO and T-GO catalysts was evaluated by using a rotating ring-disk electrode (RRDE) to perform cyclic voltammograms (CVs), linear sweep voltammetry (LSV), and chronoamperometry on a CHI-660E $(\mathrm{CH}-$ Instruments, USA) using a conventional three-electrode system. Preliminarily, the glassy carbon (GC) surface (3 $\mathrm{mm}$ in diameter) was cleaned by polishing with three different sizes $(1.0,0.3,0.05 \mu \mathrm{m})$ of alumina powders simultaneously. Then, this polished GC electrode was sonicated in DI water followed by methanol to remove residual alumina particles and other organic and inorganic impurities. The T-GO modified GC electrode was used as the working electrode, with Pt wire and saturated calomel electrode (SCE) as the counter and reference electrodes respectively.

The GC electrode was modified using $2 \mathrm{mg}$ of T-GO dispersed in $0.1 \mathrm{~mL}$ of isopropyl alcohol. The electrode was sonicated for $1 \mathrm{~h}$ and a roughly $6 \mu \mathrm{L}$ drop of T-GO suspension was drop-casted on the cleaned GC electrode and dried at room temperature. The experiments were carried out at room temperature in $0.5 \mathrm{M}$ $\mathrm{KOH}$ solution. All potentials were measured $v s$. the SCE and normalized to the reversible hydrogen electrode (RHE).

\section{Results and discussion}

The structural and morphological properties of as-synthesised GO and T-GO were investigated by different microscopic and spectroscopic characterization techniques. Accordingly, Fig. 1(a) and S1 $\uparrow$ represent SEM images of T-GO and GO, both having $\sim 20 \mathrm{~nm}$ width and average sheet diameter of more than $100 \mathrm{~nm}$. Although in both cases the sheets have similar dimensions, the smaller separation between sheets found in $\mathrm{T}$ - 
GO could be due to the additional functionality of tyramine on graphene, and is in good agreement with the literature on similar systems. ${ }^{26,27}$

Fig. S7† shows the typical sheet like morphology of GO as imaged by transmission electron microscopy (TEM).

Moreover, the representative SEM image of T-GO shown in Fig. 1(b) also supports the above conclusion. To further confirm the chemical composition and information about tyramine functionalization on GO, EDAX analysis was performed, as displayed in Fig. 1(c). Accordingly, the strong signals in the C, O, and $\mathrm{N}$ regions confirm the surface functionalization of tyramine on GO. Further, the representative superimposed XRD patterns of GO and T-GO shown in Fig. 2(a) contain the standard diffraction peaks for the (002), (101) and (110) planes of GO, showing that in T-GO, negligible changes occurred after functionalization. $^{29,31}$ The FTIR spectra of GO and T-GO are shown in Fig. 2(b), where the sharp peaks corresponding to $\mathrm{O}-\mathrm{H}$ stretching centred at $3442 \mathrm{~cm}^{-1}$ are related to adsorbed water molecules and also associated with alcoholic and carboxylic acid functional groups. Moreover, the presence of other functional groups on the surface of GO can also be confirmed, for example, the $\mathrm{C}=\mathrm{C}, \mathrm{C}=$ $\mathrm{O}, \mathrm{C}-\mathrm{O}$, and $\mathrm{C}-\mathrm{H}$ bond stretching bands at $1639 \mathrm{~cm}^{-1}$, $1710 \mathrm{~cm}^{-1}, 1107-1396 \mathrm{~cm}^{-1}$, and $2917 \mathrm{~cm}^{-1}$ respectively correspond to carbon skeleton and oxidative functionalities., ${ }^{32,33}$ After surface functionalization of GO with tyramine, the intensities of hydroxy groups and the $\mathrm{C}=\mathrm{O}$ stretching band decrease, and representative stretching bands are observed at $1580 \mathrm{~cm}^{-1}$ and $3210 \mathrm{~cm}^{-1}$, corresponding to $\mathrm{CO}-\mathrm{NH}$ and $\mathrm{N}-\mathrm{H}$ of T-GO. ${ }^{34-36}$

Raman spectroscopy is the most immediate and nondestructive method to describe the structure and nature of carbon-based materials. Accordingly, Fig. 3(a) represents the superimposed Raman spectra for GO and T-GO, with representative bands at $1345 \mathrm{~cm}^{-1}$ and $1343 \mathrm{~cm}^{-1}$ for the $\mathrm{D}$ band and $1572 \mathrm{~cm}^{-1}$ and $1570 \mathrm{~cm}^{-1}$ for the $\mathrm{G}$ band for GO and T-

(a)
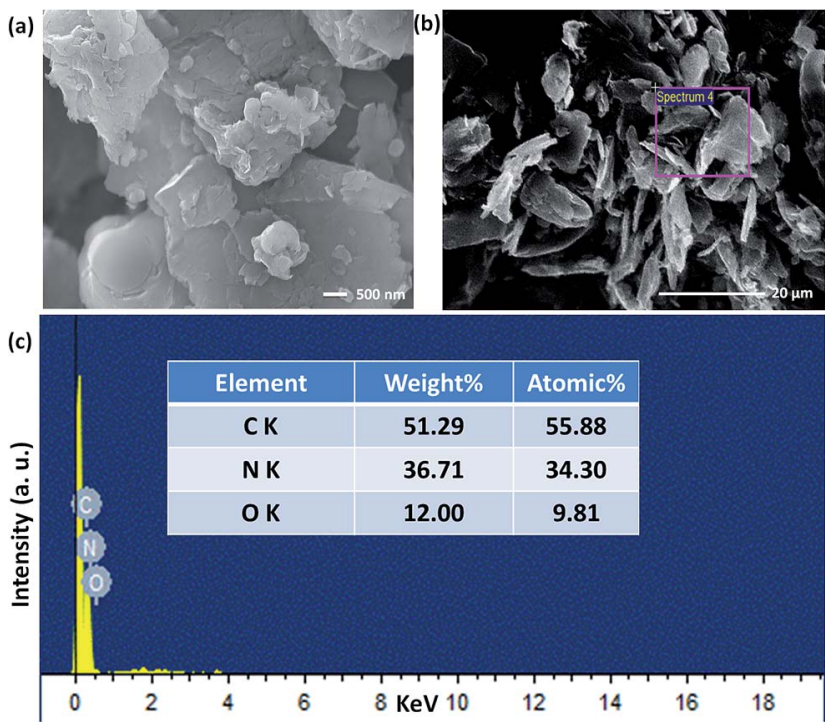

Fig. 1 Scanning electron microscopic images of (a) and (b) T-GO (different magnification) and (c) EDAX of T-GO confirms $\mathrm{C}, \mathrm{N}$ and $\mathrm{O}$.
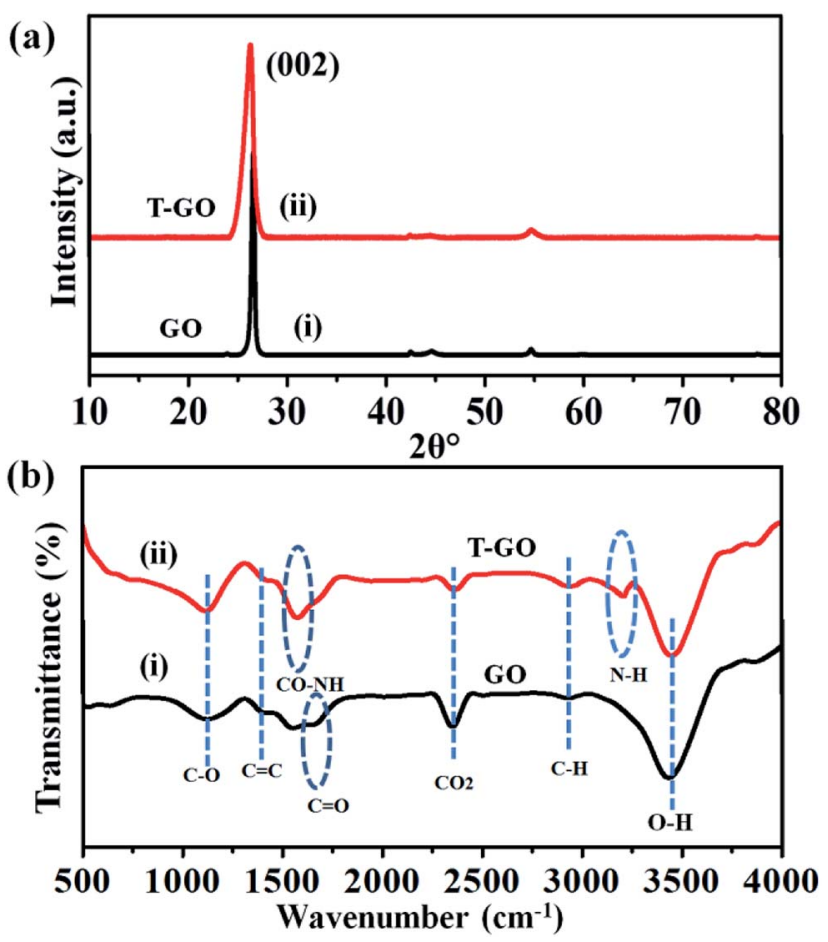

Fig. 2 Superimposed (a) XRD patterns and (b) FTIR spectra of asprepared $\mathrm{GO}$ and $\mathrm{T}-\mathrm{GO}$.

GO respectively. ${ }^{37-39}$ Also, the characteristic $2 \mathrm{D}$ bands of T-GO and GO are at $2677 \mathrm{~cm}^{-1}$ and $2669 \mathrm{~cm}^{-1}$ respectively. Interestingly, the intensity ratio $I_{\mathrm{D}} / I_{\mathrm{G}}$ for GO and T-GO is 0.18
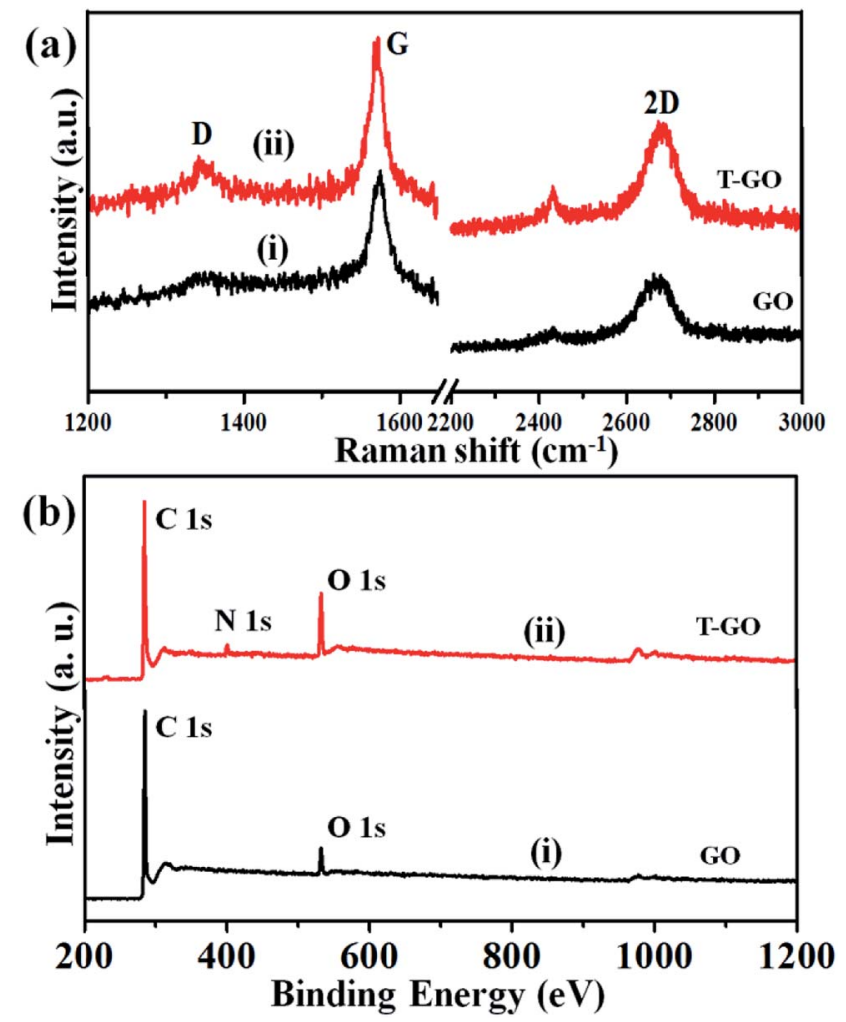

Fig. 3 (a) Raman spectra and (b) full scan XPS spectra for GO (i) and T$\mathrm{GO}$ (ii). 
and 0.32 respectively. ${ }^{\mathbf{4 0 , 4 1}}$ This increase in $I_{\mathrm{D}} / I_{\mathrm{G}}$ ratio for T-GO suggests a greater degree of disorder in T-GO after functionalization. ${ }^{42}$

The GO and T-GO were further characterized by XPS. Accordingly, high-resolution C 1s spectra for GO and T-GO are shown in Fig. S2(a), $\dagger$ where the spectral signals obtained at $284.8 \mathrm{eV}, 286.1 \mathrm{eV}$, and $289.1 \mathrm{eV}$ correspond to the $\mathrm{C}-\mathrm{C}, \mathrm{C}-\mathrm{O}$, and $(\mathrm{C}(\mathrm{O}) \mathrm{OH})$ groups respectively for the GO. ${ }^{43-45}$ Moreover, after the functionalization by tyramine, an additional signal is observed at $286.1 \mathrm{eV}$, corresponding to $\mathrm{C}-\mathrm{N}$, as shown in Fig. S2(b) † for the TGO. This confirms that tyramine functionalization occurs through amide (CO-NH) linkages and is also in good agreement with the above FT-IR findings. Moreover, the $\mathrm{O}$ 1s spectra of GO and T-GO, featuring peaks at $532.9 \mathrm{eV}, 531.3 \mathrm{eV}, 532.2 \mathrm{eV}$ and $533.6 \mathrm{eV}$ corresponding to the $\mathrm{C}-\mathrm{OH}, \mathrm{C}-\mathrm{O}-\mathrm{C}, \mathrm{C}=\mathrm{O}$, and $\mathrm{C}-\mathrm{OH}$ groups respectively, are shown in Fig. S3(a) and (b). $\uparrow^{\mathbf{2 9 , 4 6 , 4 7}}$ Meanwhile, the N 1s spectrum for T-GO shown in Fig. S4† was obtained to probe the surface functionalization of tyramine on the graphene oxide surface of T-GO. Accordingly, the representative signals at $399.5 \mathrm{eV}$ and $401.0 \mathrm{eV}$ correspond to the $\mathrm{NH}-\mathrm{C}=$ $\mathrm{O}$ and $\mathrm{C}-\mathrm{N}$ groups respectively. ${ }^{48-50}$ The wide scan XPS spectra of GO (i) and T-GO (ii) shown in Fig. 3(b) confirm the functionalization of tyramine on GO from the additional signal corresponding to $\mathrm{N}$ appearing in T-GO.

Further, thermogravimetric analysis (TGA) for GO and T-GO was performed under nitrogen atmosphere in the range of 30 to $1000{ }^{\circ} \mathrm{C}$ with temperature ramp rate of $20{ }^{\circ} \mathrm{C} \mathrm{min}^{-1}$ (Fig. S5 $\dagger$ ). For GO and T-GO there are three stages of weight loss. In GO the weight loss in the first stage at about $387.71{ }^{\circ} \mathrm{C}$ is the removal of epoxy and oxygen containing functional groups associated with water molecules. The weight loss in the second stage at $591.30{ }^{\circ} \mathrm{C}$ involves $80 \%$ of the remaining mass, including functionalities like $\mathrm{sp}^{3}$ hybridised carbon atoms and phenolic groups that are also present on the surface of GO. After the functionalization by tyramine on the surface of GO, the thermal stability increases and the main weight loss occurs at $466{ }^{\circ} \mathrm{C}$. This could be due to additional stability from amide formation and is in good agreement with similar studies. ${ }^{50}$ These results indicated the high degree of oxidation of the chemically prepared graphite in GO and T-GO. Thus, we can infer that the oxygen moieties are replaced by tyramine molecules after the amidation reaction of GO, in agreement with the above findings, especially Raman data.

AFM imaging was used to characterize the surface morphology and thickness of GO. Fig. S8 $\uparrow$ shows the AFM three dimensional image of GO, clearly showing sheets with some wrinkles and an average thickness of about $0.30 \mathrm{~nm}$, indicating formation of single layered GO nanosheets. ${ }^{51}$

\subsection{Electrochemical studies and reaction mechanism of OER}

Electrocatalytic studies of GO and T-GO based electrocatalytic systems were performed in solutions of $0.5 \mathrm{M} \mathrm{KOH}$ as shown in Fig. 4(a).

Accordingly, the LSV measurements show that T-GO shows excellent electrocatalytic activity compared with GO/GCE and also several times better than bare GCE. Interestingly, due to the
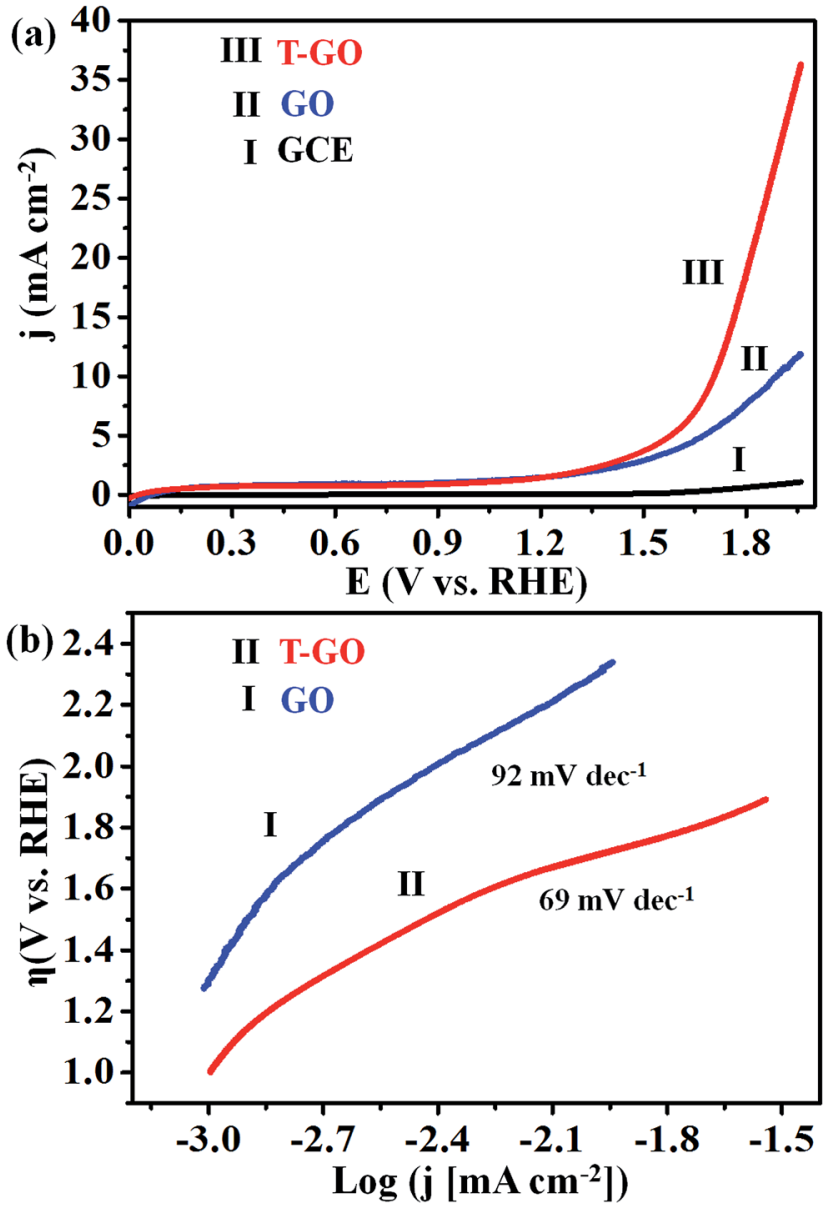

Fig. 4 Superimposed (a) LSV of (I) GCE (bare), (II) GO and (III) T-GO, (b) Tafel plots for (II) T-GO and (I) GO in $0.5 \mathrm{M} \mathrm{KOH}$ using SCE and Pt foil as reference and counter electrodes respectively (all potentials were normalized with RHE) at $50 \mathrm{mV} \mathrm{s}^{-1}$.

tyramine functionalization on GO, T-GO exhibits a higher density of active sites and larger surface area than GO. For example, the LSV polarization curve for T-GO affords a current density of $2 \mathrm{~mA} \mathrm{~cm}^{-2}$ at an ultralow onset potential of $\sim 1.39 \mathrm{~V}$ vs. RHE, which is lower than that of GO and GCE. After the functionalization of tyramine on GO, the current density is significantly increased and the onset potential is shifted to a lower value for the OER. The corresponding Tafel plot of T-GO is shown in Fig. 4(b), and the Tafel slopes for GO and T-GO are found to be 92 and $69 \mathrm{mV} \mathrm{dec}{ }^{-1}$ respectively, signifying that the T-GO has a considerable electrocatalytic activity towards OER as a metal-free electrocatalyst. The lower Tafel slope for the T-GO shows more facile charge transfer after functionalization of tyramine at the GO interface. This is in good agreement with earlier studies, and suggests a better performance than the reported metal free systems in the literature. Accordingly, Table 1 shows the comparative data of T-GO with other electrocatalysts using parameters like overpotential and their Tafel slope values. As displayed, the overpotential of the T-GO metal-free electrocatalyst is $176 \mathrm{mV}$ at $2 \mathrm{~mA} \mathrm{~cm}{ }^{-2}$ and the Tafel slope is $69 \mathrm{mV}$ $\mathrm{dec}^{-1}$. In comparison with the metal-free electrocatalysts and metal-supported nanocomposites in the literature, T-GO shows 
Table 1 Comparative study of T-GO with other similar electrocatalysts towards oxygen evolution reaction (OER) in aq. KOH as an electrolytic solution

\begin{tabular}{|c|c|c|c|c|}
\hline $\begin{array}{l}\text { Carbon based catalyst } \\
\text { system }(\mathrm{nm})\end{array}$ & $\begin{array}{l}\text { Electrolyte } \\
\text { concentration }\end{array}$ & $\begin{array}{l}\text { Overpotential } \\
\text { (mV vs. RHE) }\end{array}$ & $\begin{array}{l}\text { Tafel slope } \\
\left(\mathrm{mV} \mathrm{dec}^{-1}\right)\end{array}$ & Ref. \\
\hline NFPGNS & $1 \mathrm{M}$ & NA & 78 & $4 c$ \\
\hline CNTBN5-750 & $0.1 \mathrm{M}$ & NA & 122 & $22 a$ \\
\hline $\mathrm{CuNi}-\mathrm{C}$ & $1 \mathrm{M}$ & 408 & 83 & 54 \\
\hline Co/Mo & $0.1 \mathrm{M}$ & 270 & 87 & 55 \\
\hline PEG-CoO & $0.1 \mathrm{M}$ & 348 & 79 & 57 \\
\hline NiMoO-SP/Ti & $1 \mathrm{M}$ & 280 & 85 & 58 \\
\hline Co-Ni-B@NF & NA & 313 & 120 & 59 \\
\hline T-GO & $0.5 \mathrm{M}$ & 176 & 69 & This work \\
\hline
\end{tabular}

excellent electrochemical OER performance. Moreover, the CVs for GO and T-GO were also recorded, as shown in Fig. S6, $\uparrow$ and the comparative data are in line with the above findings.

Next, the stability of T-GO was investigated further by chronoamperometric measurement at an applied potential of $1.39 \mathrm{~V}$ vs. RHE for $3600 \mathrm{~s}$ as shown in Fig. 5(a). Moreover, the inset of Fig. 5(a) shows the superimposed LSV curves before and after chronoamperometric measurement, which demonstrates there
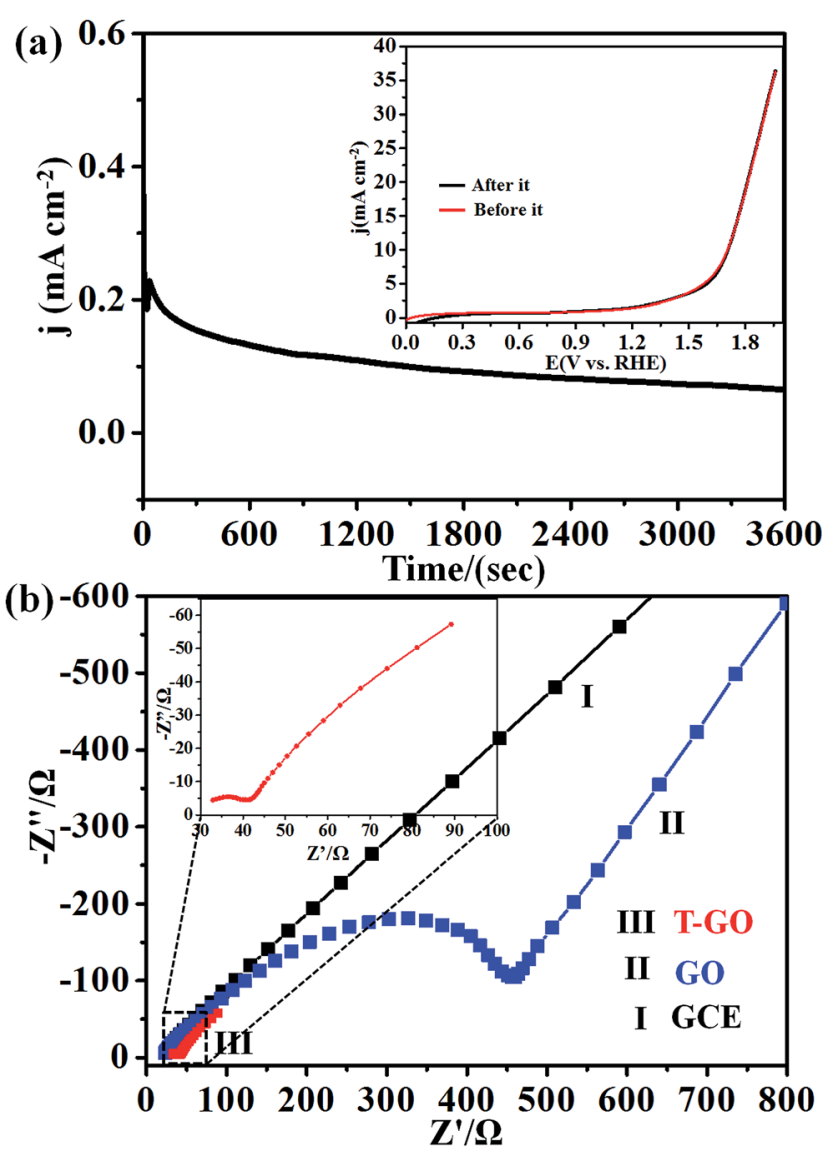

Fig. 5 (a) Electrochemical chronoamperometric current stability at applied potential $1.39 \mathrm{~V}$ vs. RHE for $3600 \mathrm{~s}$; inset shows superimposed LSV curves before and after these stability measurements for T-GO at $50 \mathrm{mV} \mathrm{s}^{-1}$. (b) Superimposed Nyquist plots for (I) GCE, (II) GO and (III) $\mathrm{T}-\mathrm{GO}$ in $0.5 \mathrm{M} \mathrm{KOH}$ solution at applied potential of $1.39 \mathrm{~V}$ vs. RHE. is no significant change in onset potential and current density after and before electrolysis for $3600 \mathrm{~s}$. These findings suggest the excellent stability and reproducibility of the T-GO metal-free electrocatalyst during the OER, in good agreement with similar reports in the literature on other OER electrocatalysts. The comparison of metal-free T-GO and other electrocatalysts is summarized in Table 1 and clearly shows that compared with those electrocatalysts in the reported literature, TGO has excellent performance for OER. ${ }^{51-59}$ This promoted activity could be due to the availability of additional surface-active sites due to tyramine, which supports enhanced electron transfer capabilities. $^{29}$

The probable mechanistic pathway for OER on the surface of T-GO is shown in Scheme 2. Interestingly, herein the active sites of T-GO for electrocatalytic OER involve four consecutive one electron oxidation processes. In the first step of the reaction, a hydroxyl $(\mathrm{OH})$ radical is adsorbed on the active site of T-GO, which results in formation of the intermediate T-GO-OH, by oxidation (removal of $1 \mathrm{e}^{-}$) of a hydroxide anion. This is followed by the formation of T-GO-O ${ }^{-}$by the removal of a proton and an electron simultaneously from the T-GO-OH species. In the next

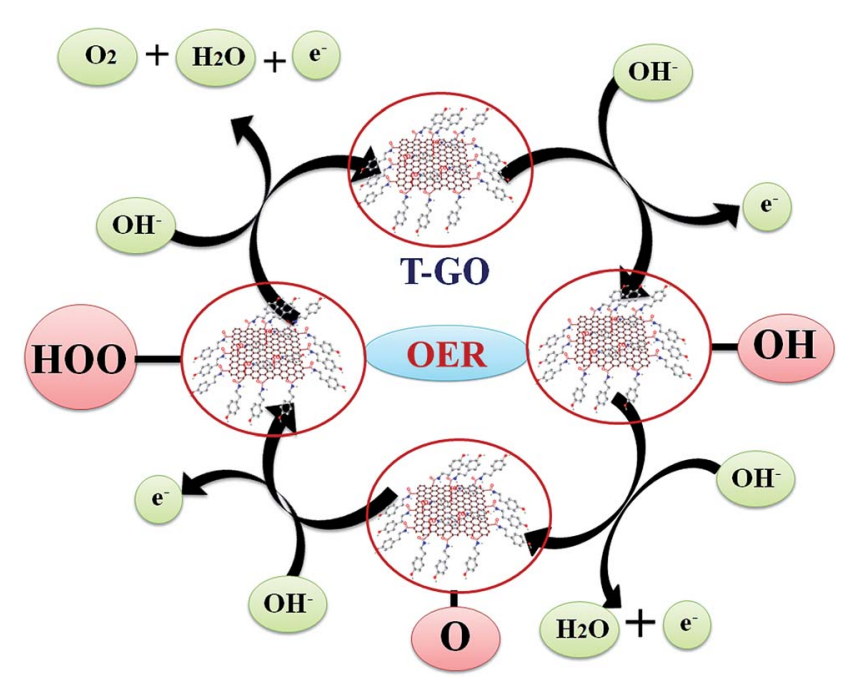

Scheme 2 Reaction mechanism for probable electron transfer pathways for OER on T-GO in $0.5 \mathrm{M} \mathrm{KOH}$. 


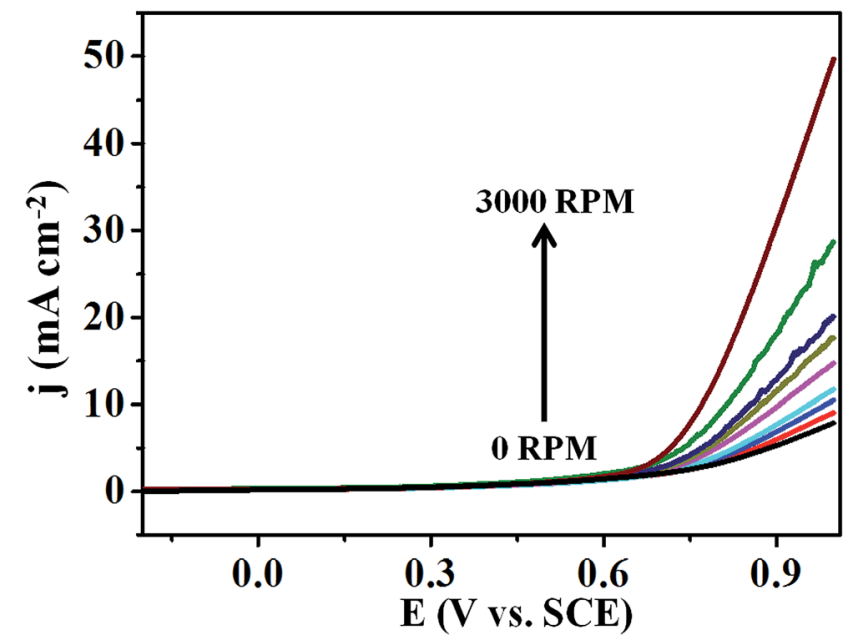

Fig. 6 Superimposed LSV curves of T-GO in $0.5 \mathrm{M} \mathrm{KOH}$ with different rotating rates from 0 to $3000 \mathrm{rpm}$.

step, a hydroxyl anion combines with T-GO-O ${ }^{-}$to give the hydroperoxide intermediate T-GO-OOH. Then, proton-coupled electron transfer results in the $\mathrm{O}_{2}$ molecule species. ${ }^{6 b, 9 b, 10 c, 27 a, 60-62}$ The electrochemical mechanisms of OER in metal free systems are more complex than in metal systems.

In addition, the OER kinetics of the GO and T-GO electrode/ electrocatalyst interface was studied via electrochemical impedance spectroscopy (EIS). Fig. 5(b) shows the Nyquist plots for bare GCE, GO and T-GO, each featuring two semicircles. The semicircles at the low- and high-frequency range in the Nyquist plots are attributed to the internal resistance $R_{\mathrm{s}}$ and charge transfer resistance $R_{\text {ct }}$ respectively. The semicircle at low frequency is significantly reduced in surface functionalized electrocatalysts. ${ }^{63-65}$ Accordingly, T-GO showed a lower $R_{\mathrm{ct}}$ value than GO, suggesting a lower frequency and higher charge transport efficiency for T-GO as compared to GO. This implies that the tyramine functionality enhances the electrocatalytic activity by boosting the electron transfer rate at the electrode interface. $^{29}$

Moreover, Fig. 6 represents the LSV curves for T-GO at different rotation speeds from 0 to $3000 \mathrm{rpm}$ for OER investigated in $0.5 \mathrm{M} \mathrm{KOH}$. With an increase in rotation speed, the current increases to $0.9 \mathrm{~mA} \mathrm{~cm}{ }^{-2}$ (for $3000 \mathrm{rpm}$ ), which indicates diffusion controlled OER on the T-GO based systems.

\section{Conclusions}

In summary, we reported a novel synthetic approach for fabrication of metal free tyramine functionalized GO (T-GO) having a large number of active sites and very high surface area. Efficient electrocatalytic activity towards OER and very good stability was found after tyramine functionalization on GO. XPS, TGA and FTIR data reveal that the existence of tyramine on the surface of GO plays a critical role in tuning the surface structure while increasing the number of active sites on the surface of TGO. We believe that this enhanced activity after tyramine functionalization, i.e. $176 \mathrm{mV}$ overpotential to afford $2 \mathrm{~mA} \mathrm{~cm}^{-2}$ current density and a low Tafel slope of $69 \mathrm{mV} \mathrm{dec}^{-1}$, could be due to having tyramine functionalities on the surface, which promotes electron transfer at the interface leading to enhanced OER compared to GO. Hence, T-GO is a promising electrocatalyst having good stability, low cost and effective electrocatalytic performance for OER applications.

\section{Conflicts of interest}

There are no conflicts to declare.

\section{Acknowledgements}

The financial support by Council of Scientific and Industrial Research (CSIR), New Delhi, India, for providing JRF and SRF Fellowship, FAST TRACK DST-SERB (SERB/F/7963/2014-15) New Delhi (India), DAE-BRNS, Mumbai (India) research project (Ref F. No. 34/20/06/2014-BRNS/21gs) and DST-SERB New Delhi (India) research project (Ref F. No. SERB/F/7490/2016-17) is greatly acknowledged. We are also thankful to the Department of Chemistry, Dr. Babasaheb Ambedkar Marathwada University, Aurangabad-431004 (MS) India for providing the laboratory facility.

\section{References}

1 (a) M. A. Sayeed and A. P. O'Mullane, J. Mater. Chem. A, 2017, 5, 23776-23784; (b) C. Teng, X. Yang, C. Yang, S. Li, M. Cheng, A. Hagfeldt and L. Sun, J. Phys. Chem. C, 2010, 114, 9101-9110.

2 C. Jin, F. Lu, X. Cao, Z. Yang and R. Yang, J. Mater. Chem. A, 2013, 1, 12170-12177.

3 (a) B. Seo, Y. J. Sa, J. Woo, K. Kwon, J. Park, T. J. Shin, H. Y. Jeong and S. H. Joo, ACS Catal., 2016, 6, 4347-4355; (b) S. Cui, X. Liu, Z. Sun and P. Du, ACS Sustainable Chem. Eng., 2016, 4, 2593-2600.

4 (a) R. V. Digraskar, V. S. Sapner, S. S. Narwade, S. M. Mali, A. V. Ghule and B. R. Sathe, RSC Adv., 2018, 8, 2034120346; (b) X. Zou, X. Huang, A. Goswami, R. Silva, B. R. Sathe, E. Mikmekov and T. Asefa, Angew. Chem., Int. Ed., 2014, 53, 4372-4376; (c) X. Yue, S. Huang, J. Cai, Y. Jin and P. K. Shen, J. Mater. Chem. A, 2017, 5, 7784-7790.

5 (a) L. Jiao, Y. Zhou and H. L. Jiang, Chem. Sci., 2016, 7, 16901695; (b) V. Maruthapandian, M. Mathankumar, V. Saraswathy, B. Subramanian and S. Muralidharan, ACS Appl. Mater. Interfaces, 2017, 9, 13132-13141; (c) Z. Tao, T. Wang, X. Wang, J. Zheng and X. Li, ACS Appl. Mater. Interfaces, 2016, 8, 35390-35397; (d) Y. Zhang, X. Fan, J. Jian, D. Yu, Z. Zhang and L. Dai, Energy Environ. Sci., 2017, 10, 2312-2317.

6 (a) B. R. Sathe, RSC Adv., 2013, 3, 5361-5365; (b) D. R. Kauffman, D. Alfonso, D. N. Tafen, J. Lekse, C. Wang, X. Deng, J. Lee, H. Jang, J. S. Lee, S. Kumar and C. Matranga, ACS Catal., 2016, 6, 1225-1234; (c) M. S. Burke, L. J. Enman, A. S. Batchellor, S. Zou and S. W. Boettcher, Chem. Mater., 2015, 27, 7549-7558; (d) S. S. Narwade, B. B. Mulik, S. M. Mali and B. R. Sathe, Appl. Surf. Sci., 2017, 396, 939-944. 
7 (a) J. R. Galán-Mascarós, ChemElectroChem, 2015, 2, 37-50; (b) Y. Yan, B. Y. Xia, B. Zhao and X. Wang, J. Mater. Chem. A, 2016, 4, 17587-17603; (c) R. V. Digraskar, B. B. Mulik, P. S. Walke, A. V. Ghule and B. R. Sathe, Appl. Surf. Sci., 2017, 412, 475-481.

8 (a) D. K. Bediako, Y. Surendranath and D. G. Nocera, J. Am. Chem. Soc., 2013, 135, 3662-3674; (b) J. Zhang, Z. Xia and L. Dai, Sci. Adv., 2015, 1, e1500564; (c) M. Qian, S. Cui, D. Jiang, L. Zhang and P. Du, Adv. Mater., 2017, 29, 1704075; (d) A. T. Swesi, J. Masud and M. Nath, Energy Environ. Sci., 2016, 9, 1771-1782; (e) F. M. Sapountzi, J. M. Gracia, C. J. Weststrate, H. O. A. Fredriksson and J. W. Niemantsverdriet, Prog. Energy Combust. Sci., 2017, 58, 1-35.

9 (a) L. Chen, X. Dong, Y. Wang and Y. Xia, Nat. Commun., 2016, 7, 11741; (b) N. T. Suen, S. F. Hung, Q. Quan, N. Zhang, Y. J. Xu and H. M. Chen, Chem. Soc. Rev., 2017, 46, 337-365; (c) K. Dang, T. Wang, C. Li, J. Zhang, S. Liu and J. Gong, Engineering, 2017, 3, 285-289; (d) T. Reier, M. Oezaslan and P. Strasser, ACS Catal., 2012, 2, 1765-1772.

10 (a) J. Xu, J. Li, D. Xiong, B. Zhang, Y. Liu, K. H. Wu, I. Amorim, W. Li and L. Liu, Chem. Sci., 2018, 9, 34703476; (b) T. Zhou, Z. Cao, P. Zhang, H. Ma, Z. Gao, H. Wang, Y. Lu, J. He and Y. Zhao, Sci. Rep., 2017, 7, 46154; (c) F. Song, L. Bai, A. Moysiadou, S. Lee, C. Hu, L. Liardet and X. Hu, J. Am. Chem. Soc., 2018, 140, 7748-7759.

11 (a) Y. Gorlin and T. F. Jaramillo, J. Am. Chem. Soc., 2010, 132, 13612-13614; (b) Z. F. Huang, J. Wang, Y. Peng, C. Y. Jung, A. Fisher and X. Wang, Adv. Energy Mater., 2017, 7, 1700544; (c) S. M. Alia, S. Shulda, C. Ngo, S. Pylypenko and B. S. Pivovar, ACS Catal., 2018, 8, 2111-2120; (d) J. M. V. Nsanzimana, Y. Peng, Y. Y. Xu, L. Thia, C. Wang, B. Y. Xia and X. Wang, Adv. Energy Mater., 2018, 8, 1701475.

12 M. Görlin, P. Chernev, J. F. d. Araújo, T. Reier, S. Dresp, B. Paul, R. Krähnert, H. Dau and P. Strasser, J. Am. Chem. Soc., 2016, 138, 5603-5614.

13 (a) S. Banerjee, S. Debata, R. Madhuri and P. K. Sharma, Appl. Surf. Sci., 2018, 449, 660-668; (b) L. Dai, Y. Xue, L. Qu, H. J. Choi and J. B. Baek, Chem. Rev., 2015, 115, 4823-4892.

14 J. Lai, A. Nsabimana, R. Luque and G. Xu, Joule, 2018, 2, 7693.

15 S. Lu, J. Pan, A. Huang, L. Zhuang and J. Lu, Proc. Natl. Acad. Sci., 2008, 105(52), 20611-20614.

16 Y. Cheng and S. P. Jiang, Prog. Nat. Sci.: Mater. Int., 2015, 25, 545-553.

17 Y. Zhao, S. Chen, B. Sun, D. Su, X. Huang, H. Liu, Y. Yan, K. Sun and G. Wang, Sci. Rep., 2015, 5, 7629.

18 X. Liu, W. Liu, M. Ko, M. Park, M. G. Kim, P. Oh, S. Chae, S. Park, A. Casimir, G. Wu and J. Cho, Adv. Funct. Mater., 2015, 25, 5799-5808.

19 L. Zhang, J. Xiao, H. Wang and M. Shao, ACS Catal., 2017, 7, 7855-7865.

20 G. L. Tian, M. Q. Zhao, D. Yu, X. Y. Kong, J. Q. Huang, Q. Zhang and F. Wei, Small, 2014, 10, 2251-2259.

21 X. Zou, J. Su, R. Silva, A. Goswami, B. R. Sathe and T. Asefa, Chem. Commun., 2013, 49, 7522-7524.
22 (a) I. M. Patil, M. Lokanathan, B. Ganesan, A. Swami and B. Kakade, Chem.-Eur. J., 2017, 23, 676-683; (b) X. Wang, L. Zhi, N. Tsao, Z. Tomovic, J. Li and K. Mullen, Angew. Chem., Int. Ed., 2008, 47, 2990-2992; (c) L. Q. Hoa, M. C. Vestergaard and E. Tamiya, Sensors, 2017, 17, 2587.

23 (a) B. Chen, R. Li, G. Ma, X. Gou, Y. Zhu and Y. Xia, Nanoscale, 2015, 7, 20674-20684; (b) X. Liu and L. Dai, Nat. Rev. Mater., 2016, 1, 16064.

24 J. Zhang, Z. Zhao, Z. Xia and L. Dai, Nat. Nanotechnol., 2015, 10, 444-452.

25 (a) Y. Zhao, R. Nakamura, K. Kamiya, S. Nakanishi and K. Hashimoto, Nat. Commun., 2013, 4, 2390; (b) T. Sun, J. Wang, C. Qiu, X. Ling, B. Tian, W. Chen and C. Su, Adv. Sci., 2018, 5, 1800036.

26 (a) H. Li, F. Ke and J. Zhu, Nanomaterials, 2018, 8, 89; (b) Y. Xu, M. Kraft and R. Xu, Chem. Soc. Rev., 2016, 45, 30393052.

27 (a) J. Duan, S. Chen, M. Jaroniec and S. Z. Qiao, ACS Catal., 2015, 5, 5207-5234; (b) S. Y. Sawant, T. H. Han and M. H. Cho, Int. J. Mol. Sci., 2017, 18, 25.

28 R. Li, Z. Wei and X. Gou, ACS Catal., 2015, 5, 4133-4142.

29 V. S. Sapner, P. P. Chavan, R. V. Digraskar, S. S. Narwade, B. B. Mulik, S. M. Mali and B. R. Sathe, ChemElectroChem, 2018, 5, 3191-3197.

30 W. S. Hummers and R. E. Offeman, J. Am. Chem. Soc., 1958, 80, 1339.

31 B. R. Sathe, X. Zou and T. Asefa, Catal. Sci. Technol., 2014, 4, 2023-2030.

32 X. Zhao, Y. Li, J. Wang, Z. Ouyang, J. Li, G. Wei and Z. Su, ACS Appl. Mater. Interfaces, 2014, 6, 4254-4263.

33 S. Park, K. S. Lee, G. Bozoklu, W. Cai, S. T. Nguyen and R. S. Ruoff, ACS Nano, 2008, 2, 572-578.

34 B. Y. Xu, Z. Liu, X. Zhang, Y. Wang, J. Tian, Y. Huang, Y. Ma, X. Zhang and Y. Chen, Adv. Mater., 2009, 21, 1275-1279.

35 H. Cao, X. Wu, G. Yin and J. H. Warner, Inorg. Chem., 2012, 51, 2954-2960.

36 N. Li, A. Than, X. Wang, S. Xu, L. Sun, H. Duan, C. Xu and P. Chen, ACS Nano, 2016, 10, 3622-3629.

37 S. Perumbilavil, P. Sankar, T. P. Rose and R. Philip, Appl. Phys. Lett., 2015, 107, 051104.

38 S. G. Kim, O. K. Park, J. H. Lee and B. C. Ku, Carbon Lett., 2013, 14, 247-250.

39 K. N. Kudin, B. Ozbas, H. C. Schniepp, R. K. Prud'homme, I. A. Aksay and R. Car, Nano Lett., 2008, 8, 36-41.

40 Y. Wang, L. Zhou, S. Wang, J. Li, J. Tang, S. Wang and Y. Wang, RSC Adv., 2016, 6, 69815-69821.

41 N. Wu, X. She, D. Yang, X. Wu, F. Su and Y. Chen, J. Mater. Chem., 2012, 22, 17254-17261.

42 H. Abdali and A. Ajji, Polymers, 2017, 9, 453.

43 E. Pervaiz, A. K. Tareen and M. Yang, Nano Adv., 2017, 2, 1-7. 44 F. Liu, L. Wu, Y. Song, W. Xia and K. Guo, RSC Adv. , 2015, 5, 45987-45995.

45 A. Ganguly, S. Sharma, P. Papakonstantinou and J. Hamilton, J. Phys. Chem. C, 2011, 115, 17009-17019.

46 D. A. Pethsangave, R. V. Khose, P. H. Wadekar and S. Some, ACS Appl. Mater. Interfaces, 2017, 9, 35319-35324. 
47 D. A. Pethsangave, R. V. Khose, A. C. Chaskar, S. C. Jun and S. Some, ChemistrySelect, 2016, 1, 6933-6940.

48 C. C. Caliman, A. F. Mesquita, D. F. Cipriano, J. C. C. Freitas, A. A. C. Cotta, W. A. A. Macedo and A. O. Porto, RSC Adv., 2018, 8, 6136-6145.

49 H. J. Sun, B. Liu, T. J. Peng and X. L. Zhao, Materials, 2018, 11, 647.

50 (a) C. Yuan, W. Chen and L. Yan, J. Mater. Chem., 2012, 22, 7456-7460; (b) A. Navaee and A. Salimi, RSC Adv., 2015, 5, 59874-59880; (c) B. O. C. Compton, D. A. Dikin, K. W. Putz, L. C. Brinson and S. T. Nguyen, Adv. Mater., 2010, 22, 892-896.

51 (a) A. M. Farah, F. T. Thema and E. D. Dikio, Int. J. Electrochem. Sci., 2012, 7, 5069-5083; (b) J. Shen, M. Wang, T. He, J. Jiang and M. Hu, Chem. Commun., 2018, 54, 90199022.

52 X. Du, N. Lia and X. Zhang, Dalton Trans., 2018, 47, 1207112074.

53 H. Liang, D. Jiang, S. Wei, X. Cao, T. Chen, B. Huo, Z. Peng, C. Li and J. Liu, J. Mater. Chem. A, 2018, 6, 16235-16245.

54 Z. Xie and Y. Wang, Ionics, 2018, 24, 1773-1780.

55 Y. Li, X. Ge, L. Wang, J. Liu, Y. Wang and L. Feng, RSC Adv., 2017, 7, 11568-11571.

56 (a) Z. Pu, Y. Luo, A. M. Asiri and X. Sun, ACS Appl. Mater. Interfaces, 2016, 8, 4718-4723; (b) G. Jia, Y. Hu, Q. Qian,
Y. Yao, S. Zhang, Z. Li and Z. Zou, ACS Appl. Mater. Interfaces, 2016, 8, 14527-14534.

57 Y. Zhao, B. Sun, X. Huang, H. Liu, D. Su, K. Sun and G. Wang, J. Mater. Chem. A, 2015, 3, 5402-5408.

58 Y. Wang, T. Williams, T. Gengenbach, B. Kong, D. Zhao, H. Wang and C. Selomulya, Nanoscale, 2017, 9, 17349-17356.

59 N. Xu, G. Cao, Z. Chen, Q. Kang, H. Dai and P. Wang, J. Mater. Chem. A, 2017, 5, 12379-12384.

60 R. L. Doyle and M. E. G. Lyons, Phys. Chem. Chem. Phys., 2013, 15, 5224-5237.

61 H. M. A. Amin and H. Baltruschat, Phys. Chem. Chem. Phys., 2017, 19, 25527-25536.

62 S. N. Faisal, E. Haque, N. Noorbehesht, H. Liu, Md. M. Islam, L. Shabnam, A. K. Roy, E. Pourazadi, M. S. Islam, A. T. Harris and A. I. Minett, Sustainable Energy Fuels, 2018, 2, 20812089.

63 B. Debnath, A. Kumar, H. G. Salunke and S. Bhattacharyya, J. Phys. Chem. C, 2017, 121(45), 25594-25602.

64 S. C. Riha, B. M. Klahr, E. C. Tyo, S. Seifert, S. Vajda, M. J. Pellin, T. W. Hamann and A. B. F. Martinson, ACS Nano, 2013, 7, 2396-2405.

65 M. Gao, W. Sheng, Z. Zhuang, Q. Fang, S. Gu, J. Jiang and Y. Yan, J. Am. Chem. Soc., 2014, 136, 7077-7084. 